\title{
Expression of the transcription factor CTCF in invasive breast cancer: a candidate gene located at 16q22. I
}

\author{
EA Rakha', SE Pinder', CE Paish' and IO Ellis*,I \\ 'The Breast Unit, Department of Histopathology, Nottingham City Hospital NHS Trust, Hucknall Road, University of Nottingham, \\ Nottingham NG5 IPB, UK
}

\begin{abstract}
CTCF is a ubiquitous II-zinc-finger protein that plays a role in gene silencing or activation, chromatin insulation and genomic imprinting. The CTCF gene has been mapped to the chromosome band I6q22.I that shows frequent loss of heterozygosity in breast cancer. The E-cadherin gene is the known tumour suppressor gene (TSG) at this region in lobular carcinomas; however, the target gene in the more frequent ductal tumours is still unknown. Since CTCF targets include TSGs and oncogenes and it has the ability to inhibit cell growth and proliferation, it has been suggested that it may be the target gene at the 16 q22.I in ductal carcinomas. In the present study, tissue microarray technology was used to study the expression pattern of CTCF immunohistochemically in 344 cases of invasive breast carcinoma and its expression was correlated with clinicopathological variables and patient outcome. Results showed that breast tissues express CTCF in the parenchymal cells of the normal ducts and lobules but with a variable percentage of positive cells. Staining of CTCF was detected in the nuclei and cytoplasm of the malignant cells, but no significant loss or decrease of expression was noticed in association with any specific tumour type. There was a significant correlation between expression of CTCF and histological grades; lower expression was associated with grade 3 tumours. Cytoplasmic expression was associated with increased tumour size and with the presence of vascular invasion. However, no association was found between CTCF expression and tumour type, lymph node stage, oestrogen receptor expression or patient outcome. In conclusion, the current results show that CTCF, although it may play a role in breast carcinogenesis, is unlikely to be the TSG targeted by the 16q22.I loss in breast cancer and thus another gene or genes at this region remain to be identified.

British Journal of Cancer (2004) 91, I59I-1596. doi:I0.1038/sj.bjc.6602I44 www.bjcancer.com
\end{abstract}

Published online 31 August 2004

(c) 2004 Cancer Research UK

Keywords: breast cancer; chromosome 16; CTCF; immunohistochemistry

Loss of heterozygosity (LOH) at the long arm of chromosome 16 (16q) is one of the most frequent somatic genetic events in both lobular and ductal carcinomas of the breast (Skirnisdottir et al, 1995; Cleton-Jansen et al, 2001). The smallest region of overlap at $16 \mathrm{q}$ in breast cancer has been located at 16q22.1 (Frengen et al, 2000 ), indicating the presence of a tumour suppressor gene (TSG) at this region. In the search for the target gene, E-cadherin has been proven to be the TSG by the identification of gene mutations and loss of protein expression, but only in the lobular type carcinomas (Kanai et al, 1994; Berx et al, 1995; Berx et al, 1998; Acs et al, 2001). Thus, another TSG (s) is the target of 16q22.1 LOH in the more frequent ductal carcinomas that remains to be identified. Any gene located in the vicinity of $16 \mathrm{q} 22.1$ could be considered as a candidate gene and should be examined to assess its role in breast cancer.

The CTCF gene has been mapped to 16q22.1 (Filippova et al, 1998). It encodes a DNA-binding 11-zinc-finger protein that shows a highly versatile function and multiple DNA sequence specificity (Filippova et al, 1996, 1998). CTCF is a widely expressed

*Correspondence: Dr IO Ellis; E-mail: ian.ellis@nottingham.ac.uk Received 22 December 2003; revised 16 June 2004; accepted 20 July 2004; published online 31 August 2004 transcription factor that is involved in different aspects of gene regulation including promoter activation (Vostrov and Quitschke, 1997) and repression (Filippova et al, 1996), hormone-responsive gene silencing (Burcin et al, 1997), methylation-dependent chromatin insulation and genomic imprinting (Kanduri et al, 2000; Filippova et al, 2002). In addition, it has been demonstrated that CTCF can inhibit cell growth and induce cell cycle arrest at multiple stages (Rasko et al, 2001).

The tumour suppressor role of CTCF was suspected because of its involvement in regulating the expression of some genes that are directly implicated in cancer (i.e., MYC, IGF2, p53, P27, p19/ARF and BRCA 1) (Bell and Felsenfeld, 2000; Klenova et al, 2002; Qi et al, 2003), its cell growth inhibitory effect and its genetic mapping to 16q22.1. In addition, some tumour-specific mutations have been detected in some tumours including breast cancer (Ohlsson et al, 2001; Filippova et al, 2002). The role of CTCF in cancer has previously been studied in some human tumours (Takai et al, 2001; Filippova et al, 2002; Yeh et al, 2002; Aulmann et al, 2003; Ulaner et al, 2003); however, its role in breast cancer is still unclear.

If CTCF was the target gene of 16q22.1 LOH in ductal carcinoma of the breast, then we would predict that a large proportion of ductal tumours might show marked or complete loss of its expression compared with other histological types and/or with the 
normal parenchymal tissues. Thus, in the present study, protein expression of CTCF was examined immunohistochemically in a large series to assess its possible role in invasive breast cancer.

\section{MATERIALS AND METHODS}

\section{Patients and tumours}

Formalin-fixed, paraffin-embedded tissue blocks were obtained from 344 cases of invasive breast carcinoma available from the Nottingham Tenovus Primary Breast Carcinoma Series. This is a well-characterised series of primary operable invasive breast cancer that has been previously used to study a wide range of proteins including, recently, the CD59 protein (Madjd et al, 2003). Patient's clinical history and tumour characteristics including tumour type (Ellis et al, 1992), size, histological grade (Elston and Ellis, 1991), lymph node stage, Nottingham Prognostic Index (NPI) and oestrogen receptor expression were obtained from the database. Patients had a median age of 53 years (range 18-85 years). The tumours were as follows: 29 cases were pure lobular (8.4\%), 32 mixed lobular and ductal (9.3\%), 214 ductal/no special type (NST) $(62.2 \%)$, five mixed NST and special type (1.5\%), 12 tubular (3.5\%), 42 tubular mixed $(12.2 \%)$ and 10 cases miscellaneous tumour types $(2.9 \%)$. Survival data including survival time, disease-free interval, development of distant metastasis and recurrence was available for 294 patients. The median follow-up time was 49.5 months (range 5-78 months). The NPI was calculated using the following equation: NPI $=0.2$ tumour size $(\mathrm{cm})+$ grade $(1-3)+$ lymph node score $(1-3)$ (Galea et al, 1992). This index predicts the survival of patients with invasive breast cancer and may be divided into three groups: good prognosis $(\leqslant 3.4)$, moderate prognosis $(3.41-5.4)$ and poor prognosis group (>5.4) (Kollias et al, 1999).

\section{Tissue arrays and immunohistochemistry}

Tumour samples were arrayed as previously described (Kononen et al, 1998). The tissue microarray blocks were constructed in three copies, each containing one sample from a different region of the tumour. In addition, whole tumour tissue blocks from 40 cases were stained and used to examine CTCF expression in normal breast tissues. Immunohistochemical staining was performed in accordance with standard procedures on $4 \mu \mathrm{m}$-thick sections. Briefly, tissue slides were deparaffinised with xylene and then rehydrated through three changes of alcohol. Endogenous peroxidase activity was blocked by incubation in a $0.3 \%$ hydrogen peroxide/methanol buffer. Antigen retrieval was carried out by microwave treatment of the slides in sodium citrate buffer $(\mathrm{pH} \mathrm{6.0)}$ for $20 \mathrm{~min}$. Then, the slides were rinsed in Tris-buffered saline (TBS) (pH 7.6) and incubated with normal swine serum (NSS) in TBS $(1: 5)$ to block nonspecific staining. The slides were then incubated overnight with a goat polyclonal anti-CTCF antibody (Santa Cruz Biotechnology, sc-5916) and used in an optimal dilution of $1: 100\left(\mathrm{vv}^{-1}\right.$ in NSS/TBS). After washing with TBS, sections were incubated with the biotin-labelled secondary antibody $(1: 100)$ for $30 \mathrm{~min}$, and then avidin-biotin complex $(1: 100)$ for a further $45 \mathrm{~min}$. 3-3'Diaminobenzidine tetrahydrochloride was used as a chromogen and the sections were counterstained with Mayer's haematoxylin.

To verify the specificity of the CTCF immunoreactivity, blocking studies were performed by preincubation of the primary antibody (at different dilutions) for $2 \mathrm{~h}$ at room temperature with the protein fragment used to raise it (Santa Cruz Biotechnology, sc$5916 \mathrm{P})$ prior to its application to the tissues according to the supplier data sheet protocol. This abolished staining of the antibody (Figures 1 and 2). Preincubation with equivalent concentration of an irrelevant peptide had no effect on immunos-

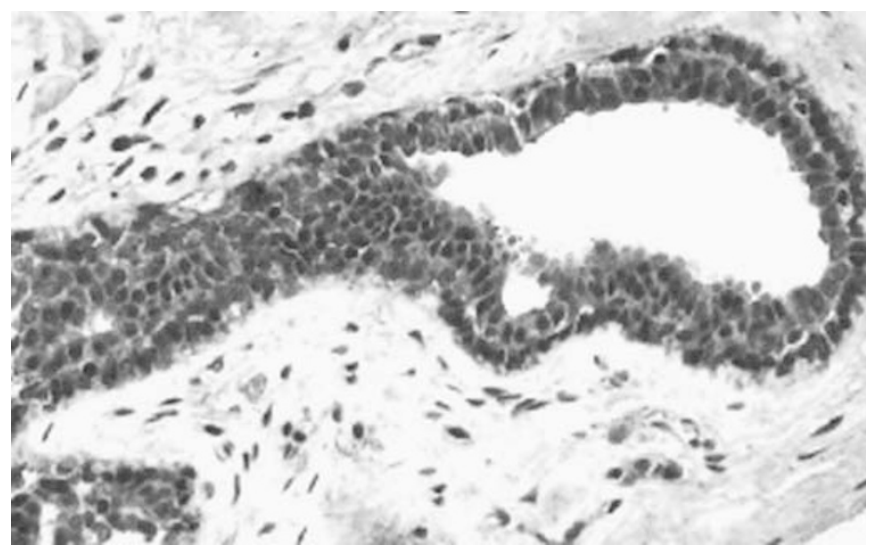

Figure I Expression of CTCF in the normal parenchymal cells of the breast (dilution of the primary antibody was I:50, overnight).

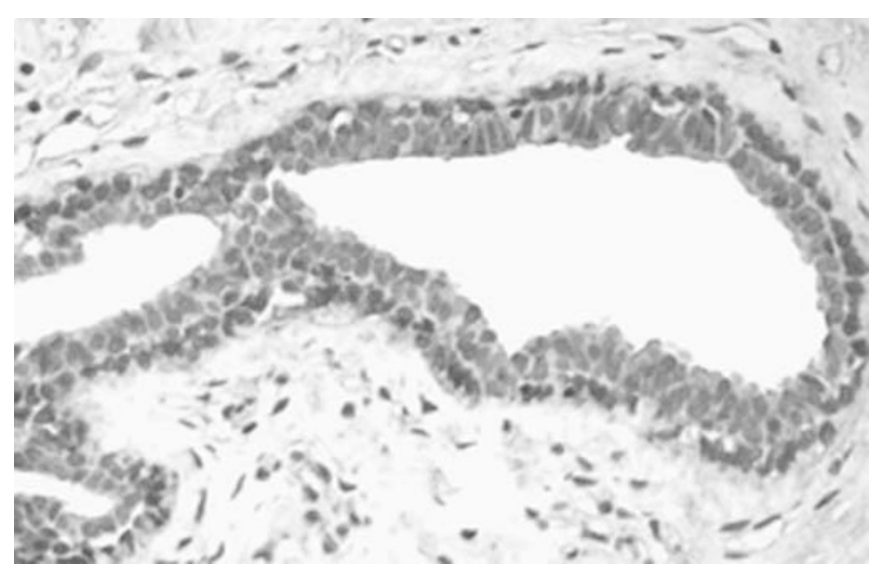

Figure 2 The same case after peptide blocking of the antibody showing marked reduction of staining.

taining. To further confirm the subcellular localisation of the CTCF protein, another primary antibody was used; a rabbit polyclonal anti-CTCF antibody (AbCam Ltd, Cambridge, UK, ab 10571) in a dilution of $1: 20$ for $2 \mathrm{~h}$ incubation using the same staining conditions as mentioned above. Negative control sections with omission of the primary antibody were included and were consistently negative. Tonsil and normal breast tissues were used as positive controls.

\section{Evaluation of immunohistochemical staining}

CTCF staining was evaluated separately in the nuclei and cytoplasm of the malignant cells. Assessment of the staining results was based on a semiquantitative approach. A modified histochemical score (H-score) was used for assessment (McCarty et al, 1985). This includes a determination of both intensity of staining and percentage of stained cells. For the intensity, a score index of 0 , 1,2 and 3 corresponding to absent, weak, moderate and strong staining intensity was used and the percentage of positive cells at each intensity was estimated. A final score of $0-300$ was the product of both the intensity and the percentage. Cutoff points of expression was determined according to the histogram distribution of the final scores. Two cores were evaluated from each tumour. Each core was scored individually, and then the mean of the two readings was calculated (Camp et al, 2000). The cases were scored without knowledge of patient data by one observer on two separate occasions and a good correlation between the results was found. 


\section{Statistical analysis}

Statistical analysis was performed using SPSS 10.0 statistical software. Associations between clinicopathological variables and expression of CTCF were analysed using the $\chi^{2}$ and Spearman rank correlation tests. Correlation between protein expression levels and overall survival and disease-free interval were analysed using Kaplan-Meier curves with the differences estimated using the Mantel-Cox log-rank test. A $P$-value of $<0.05$ was considered significant.

\section{RESULTS}

\section{CTCF expression in the breast}

Results showed that breast tissues express CTCF in the parenchymal cells of the normal ducts and lobules but with a variable percentage of positive cells. The staining pattern of the normal tissue was mainly nuclear but cytoplasmic staining was also

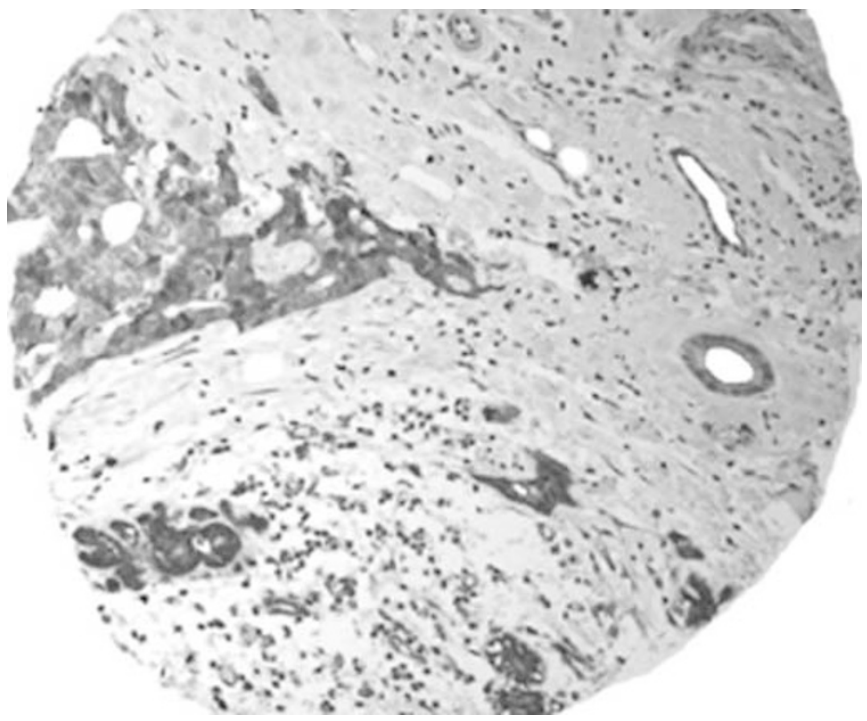

Figure 3 TMA showing expression of CTCF in the normal and malignant tissues of the breast.

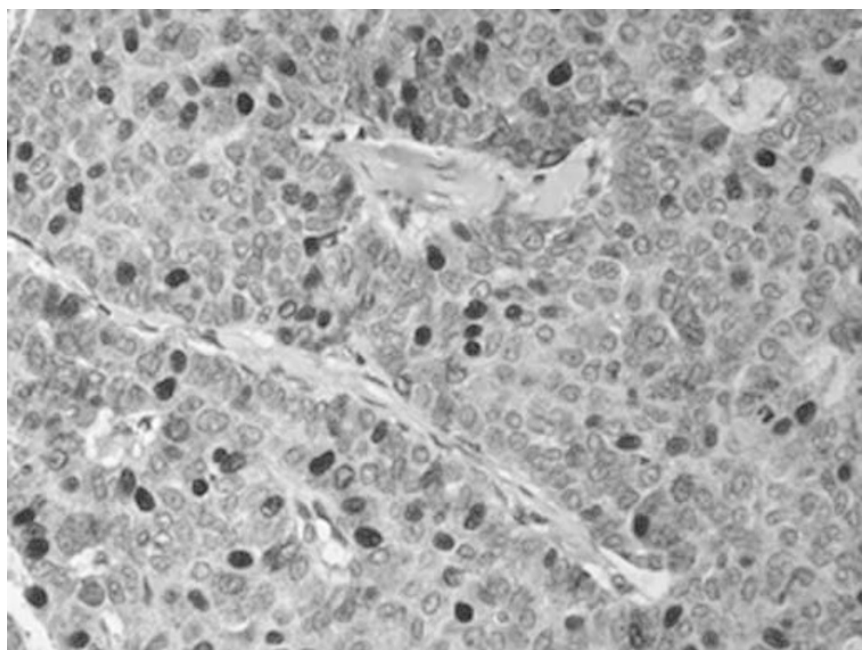

Figure 4 A case of ductal/NST carcinoma showing heterogeneous pattern of positive nuclear staining of CTCF.

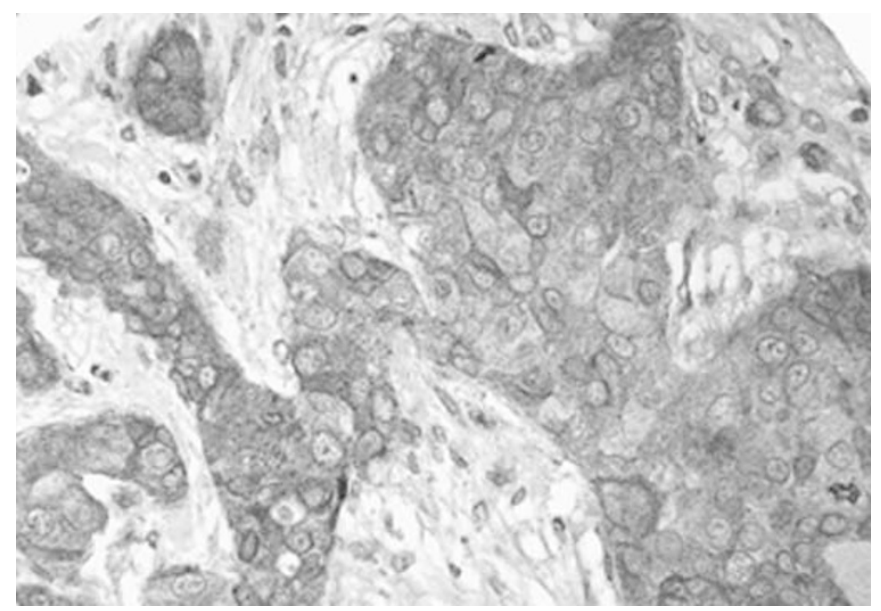

Figure 5 A case with positive cytoplasmic staining

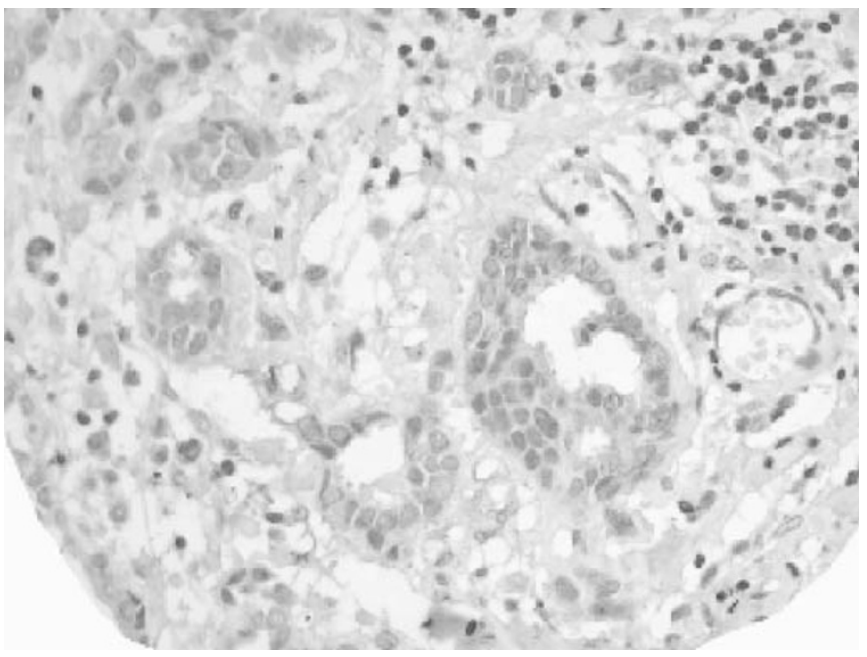

Figure 6 A case with reduced or weak staining of CTCF showing positive staining of stromal cells.

evident in some cells. No membranous staining was detected. Lymphocytes and endothelial cells showed positive staining pattern. Malignant cells showed a heterogeneous nuclear and/or cytoplasmic granular staining pattern (Figures 3-6). Normal parenchymal cells in whole tissue sections as well as normal tissue entrapped in the cores were used as internal controls. Only staining of the invasive part of the tumours was considered. Both anti-CTCF antibodies used in this study showed the same pattern of staining and a significant correlation of their staining results was noticed $(P<0.001)$.

Cases were classified according to nuclear staining into two groups; reduced $(\mathrm{H}$-score $<50), 202$ cases $(58.7 \%)$; and positive $(\geqslant 50), 142$ cases $(41.3 \%)$; and according to cytoplasmic staining into; reduced $(\mathrm{H}$-score $<100), 79$ cases $(23 \%)$; and positive $(\geqslant 50), 265$ cases $(77 \%)$. There was a significant positive correlation between nuclear and cytoplasmic staining of all cases $(r=0.618, \quad P<0.001)$. The nuclear and cytoplasmic expression of CTCF in the malignant tissue varied between cases with the positive cells varying in intensity and percentage, but no specific pattern of staining or significant loss or decrease of expression was noticed in association with any particular type of breast cancer. 
Table I Correlation between CTCF expression and clinicopathological features

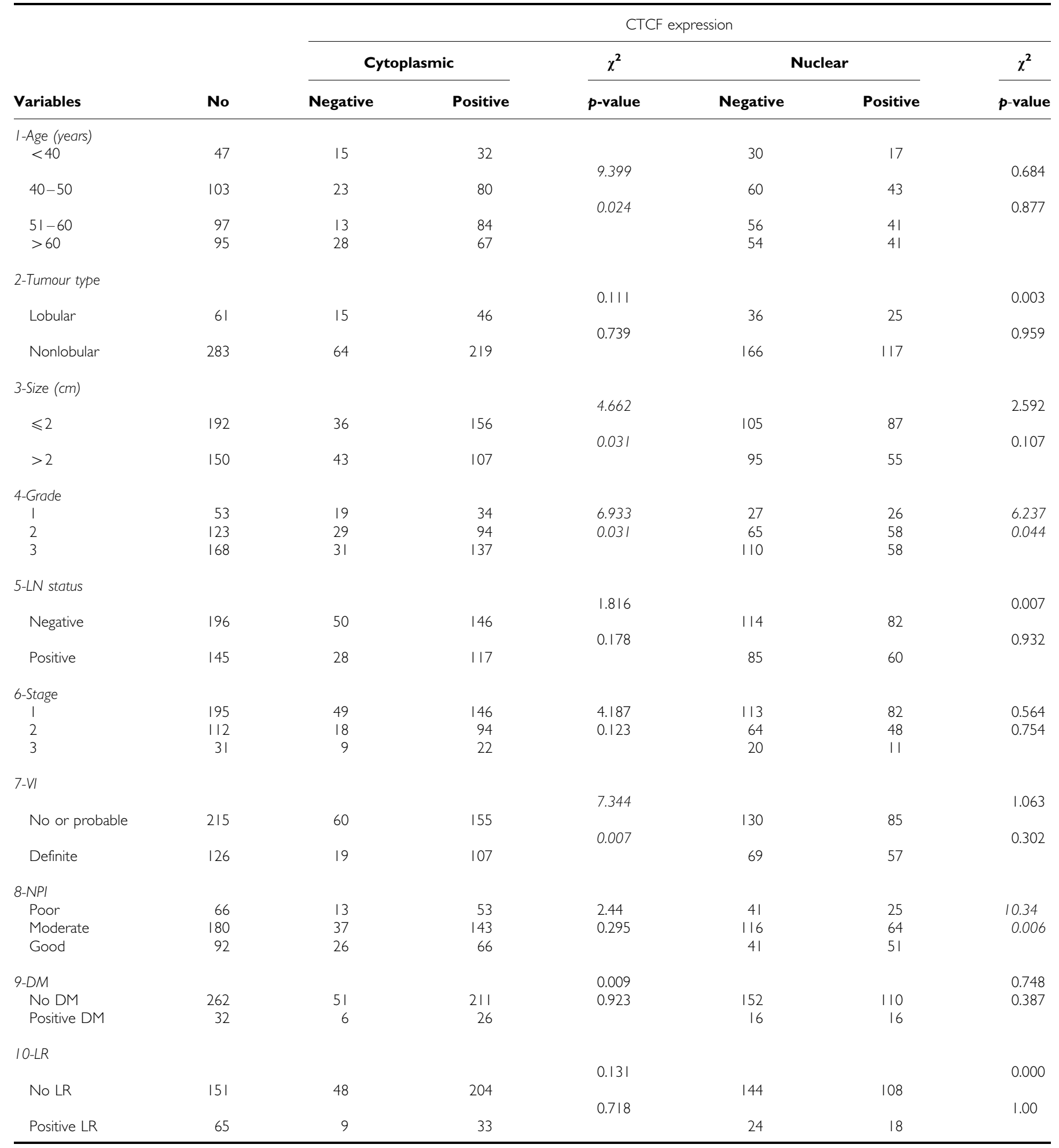

Lobular group = pure lobular and lobular mixed; Nonlobular group = ductal (NST), tubular, tubular mixed and other special types; $L N=$ lymph nodes; $V \mathrm{~V}=$ vascular invasion; $N P I=$ Nottingham Prognostic Index; DM = distant metastasis; $L R=$ local and regional recurrence. Italic = statistically significant.

\section{Correlation between CTCF expression and clinicopathological features in breast carcinoma}

Table 1 shows the relationship between nuclear and cytoplasmic expression of CTCF and the different clinicopathological features.
No correlation was found between CTCF expression and tumour type divided into two groups; lobular (pure lobular and lobular mixed) and nonlobular group (ductal, tubular, mixed and other special types), or according to its specific histologic type $\left(\chi^{2}=12.295, \quad \mathrm{df}=8, \quad P>0.138\right.$ for nuclear expression and 
Table 2 Correlation between CTCF expression and outcome

\begin{tabular}{|c|c|c|c|c|c|c|}
\hline \multirow[b]{3}{*}{ Variables } & \multicolumn{6}{|c|}{ CTCF expression } \\
\hline & \multicolumn{3}{|c|}{ Cytoplasmic } & \multicolumn{3}{|c|}{ Nuclear } \\
\hline & Log rank & df & $P$ value & Log rank & df & $P$ value \\
\hline Survival time & 1.39 & 1 & 0.238 & 0.02 & 1 & 0.887 \\
\hline Disease-free interval & 0.43 & i & 0.511 & 0.02 & i & 0.896 \\
\hline
\end{tabular}

$\mathrm{df}=$ degree of freedom

$\chi^{2}=5.109, \quad \mathrm{df}=8, \quad P>0.746$ for cytoplasmic expression). A significant association was found between nuclear and cytoplasmic expression and histological tumour grade. There was also a correlation between cytoplasmic staining and age, tumour size and the presence of vascular invasion and between nuclear staining and NPI divided into three groups as described, with greater frequency of positive cases in the good prognostic index group of patients $(P=0.006)$. However, there was no association between CTCF expression and lymph node stage, the development of distant metastasis, oestrogen receptor expression $\left(\chi^{2}=1.56, P=0.118\right.$ for nuclear expression and $\chi^{2}=0.39, P=0.694$ for cytoplasmic expression) or with patient outcome including local recurrence, survival time or disease-free interval (Table 2). No association was found between nuclear expression and age, tumour size or the presence of vascular invasion or between cytoplasmic expression and NPI.

\section{DISCUSSION}

Much effort has gone into evaluating the candidate TSG on 16q in invasive ductal carcinoma of the breast, as well as in other tumours that show frequent $\mathrm{LOH}$ of this chromosome arm. However, the relevant genes have not been identified. CTCF is a potential target gene because it has been mapped to the smallest region of overlap at $16 \mathrm{q}$ in breast cancer (16q22.1) (Filippova et al, 1998). It encodes protein involved in the transcriptional regulation of a wide variety of target genes, several of which have been reported to be involved in carcinogenesis (e.g. c-myc, p53, p27 and IGF2) (Ohlsson et al, 2001; Klenova et al, 2002). In addition, it has been shown to have a profound growth retardation effect and can inhibit cell growth and proliferation (Rasko et al, 2001). In the present study, protein expression of CTCF has been studied immunohistochemically (IHC) to evaluate its possible role in breast cancer as well as to assess its prognostic value.

Our results showed that CTCF is expressed in both the nuclei and cytoplasm of the malignant cells; nuclear expression was detected in $41 \%$ of breast cancer cases and cytoplasmic expression in $77 \%$. Immunohistochemicl staining of CTCF in invasive ductal carcinoma of the breast has previously been assessed by
Aulmann et al (2003), who reported moderate to strong nuclear staining in $94.4 \%$ (17 out of 18). However, this high percent of positive staining in their study may be related to the small number of cases.

Previous studies of CTCF using immunofluorescence showed nuclear localisation of its protein (Zhang et al, 2004), but no cytoplasmic staining has been observed. Therefore, the cytoplasmic expression detected in our study might be either due to unspecific staining or indicative of mutation affecting the nuclear translocation of CTCF protein or as a result of posttranslational modification that is commonly found to attenuate transcription factor (Hunter and Karin, 1992; Klenova et al, 2001). To rule out the first possibility, we tested the specificity of the antibody binding using peptide blocking and we tried another anti-CTCF antibody that recognises different epitope and has been used before to study the phosphorylation pattern in the C-terminus region of CTCF (Klenova et al, 2001). However, our results confirmed the specificity of the observed staining pattern.

Secondly, if this cytoplasmic expression of CTCF was an indication of mutation or inactivity that has any significant tumour suppressor role in a particular tumour type, we would expect an association between the pattern of expression (nuclear, cytoplasmic or reduced) and the tumour type. However, we could not detect any association between the intensity or pattern of expression of CTCF and tumour type and there was neither marked nor complete loss of expression in any specific type, suggesting that CTCF is not the likely TSG in breast cancer. These results are consistent with those of Yeh et al (2002) and Cui et al (2001) who could not detect mutations or loss of CTCF mRNA in Wilms' tumours and with those of Aulmann et al (2003) who used immunohistochemistry, allelic studies and mutation screen of the CTCF gene and did not find loss of CTCF protein expression in invasive ductal carcinoma of the breast.

In the current study, we detected an association between expression of CTCF and histological grade where a high percentage of low-grade tumours that have a less proliferative activity showed positive nuclear expression, while the high-grade tumours mainly showed reduced or absent expression. We also found a correlation between positive cytoplasmic expression and tumours of smaller size. These results are consistent with the previous reports that showed the ability of CTCF to inhibit cell growth and proliferation (Rasko et al, 2001). Although we found a correlation between nuclear expression of CTCF and NPI group and between cytoplasmic expression and vascular invasion, we did not find any significant correlation between its expression and other prognostic markers of breast cancer such as lymph node stage or with patient outcome.

In conclusion, our data indicate that CTCF may have a role in breast cancer progression but it is not likely to be the gene that is targeted by $16 \mathrm{q} 22.1 \mathrm{LOH}$ in breast cancer. Further studies of other genes at this region are required to identify the TSG that is the target of 16q22.1 loss in ductal carcinoma of the breast.

\section{REFERENCES}

Acs G, Lawton TJ, Rebbeck TR, LiVolsi VA, Zhang PJ (2001) Differential expression of E-cadherin in lobular and ductal neoplasms of the breast and its biologic and diagnostic implications. Am J Clin Pathol 115: $85-98$

Aulmann S, Blaker H, Penzel R, Rieker RJ, Otto HF, Sinn HP (2003) CTCF gene mutations in invasive ductal breast cancer. Breast Cancer Res Treat 80: $347-352$

Bell AC, Felsenfeld G (2000) Methylation of a CTCF-dependent boundary controls imprinted expression of the Igf2 gene. Nature 405: 482-485

Berx G, Becker KF, Hofler H, van Roy F (1998) Mutations of the human E-cadherin (CDH1) gene. Hum Mutat 12: 226-237
Berx G, Cleton-Jansen AM, Nollet F, de Leeuw WJ, van de Vijver M, Cornelisse C, van Roy F (1995) E-cadherin is a tumour/invasion suppressor gene mutated in human lobular breast cancers. EMBO J 14: $6107-6115$

Burcin M, Arnold R, Lutz M, Kaiser B, Runge D, Lottspeich F, Filippova GN, Lobanenkov VV, Renkawitz R (1997) Negative protein 1, which is required for function of the chicken lysozyme gene silencer in conjunction with hormone receptors, is identical to the multivalent zinc finger repressor CTCF. Mol Cell Biol 17: 1281-1288

Camp RL, Charette LA, Rimm DL (2000) Validation of tissue microarray technology in breast carcinoma. Lab Invest 80: 1943-1949 
Cleton-Jansen AM, Callen DF, Seshadri R, Goldup S, McCallum B, Crawford J, Powell JA, Settasatian C, van Beerendonk H, Moerland EW, Smit VT, Harris WH, Millis R, Morgan NV, Barnes D, Mathew CG, Cornelisse CJ (2001) Loss of heterozygosity mapping at chromosome arm 16q in 712 breast tumors reveals factors that influence delineation of candidate regions. Cancer Res 61: $1171-1177$

Cui H, Niemitz EL, Ravenel JD, Onyango P, Brandenburg SA, Lobanenkov VV, Feinberg AP (2001) Loss of imprinting of insulin-like growth factorII in Wilms tumor commonly involves altered methylation but not mutations of CTCF or its binding site. Cancer Res 61: 4947-4950

Ellis IO, Galea M, Broughton N, Locker A, Blamey RW, Elston CW (1992) Pathological prognostic factors in breast cancer. II. Histological type. Relationship with survival in a large study with long-term follow-up. Histopathology 20: 479-489

Elston CW, Ellis IO (1991) Pathological prognostic factors in breast cancer I. The value of histological grade in breast cancer: experience from a large study with long-term follow-up. Histopathology 19: 403-410

Filippova GN, Fagerlie S, Klenova EM, Myers C, Dehner Y, Goodwin G, Neiman PE, Collins SJ, Lobanenkov VV (1996) An exceptionally conserved transcriptional repressor, CTCF, employs different combinations of zinc fingers to bind diverged promoter sequences of avian and mammalian c-myc oncogenes. Mol Cell Biol 16: 2802-2813

Filippova GN, Lindblom A, Meincke LJ, Klenova EM, Neiman PE, Collins SJ, Doggett NA, Lobanenkov VV (1998) A widely expressed transcription factor with multiple DNA sequence specificity, CTCF, is localized at chromosome segment 16q22.1 within one of the smallest regions of overlap for common deletions in breast and prostate cancers. Genes Chromosomes Cancer 22: 26-36

Filippova GN, Qi CF, Ulmer JE, Moore JM, Ward MD, Hu YJ, Loukinov DI, Pugacheva EM, Klenova EM, Grundy PE, Feinberg AP, Cleton-Jansen AM, Moerland EW, Cornelisse CJ, Suzuki H, Komiya A, Lindblom A Dorion-Bonnet F, Neiman PE, Morse HC, Collins III SJ, Lobanenkov VV (2002) Tumor-associated zinc finger mutations in the CTCF transcription factor selectively alter its DNA-binding specificity. Cancer Res 62: $48-52$

Frengen E, Rocca-Serra P, Shaposhnikov S, Taine L, Thorsen J, Bepoldin C, Krekling M, Lafon D, Aas KK, El Moneim AA, Johansen H, Longy M, Prydz H, Dorion-Bonnet F (2000) High-resolution integrated map encompassing the breast cancer loss of heterozygosity region on human chromosome 16q22.1. Genomics 70: 273-285

Galea MH, Blamey RW, Elston CE, Ellis IO (1992) The Nottingham Prognostic Index in primary breast cancer. Breast Cancer Res Treat 22: $207-219$

Hunter T, Karin M (1992) The regulation of transcription by phosphorylation. Cell 70: $375-387$

Kanai Y, Oda T, Tsuda H, Ochiai A, Hirohashi S (1994) Point mutation of the E-cadherin gene in invasive lobular carcinoma of the breast. Jpn J Cancer Res 85: 1035 - 1039

Kanduri C, Pant V, Loukinov D, Pugacheva E, Qi CF, Wolffe A, Ohlsson R, Lobanenkov VV (2000) Functional association of CTCF with the insulator upstream of the H19 gene is parent of origin-specific and methylation-sensitive. Curr Biol 10: 853-856

Klenova EM, Chernukhin IV, El-Kady A, Lee RE, Pugacheva EM, Loukinov DI, Goodwin GH, Delgado D, Filippova GN, Leon J, Morse HC, Neiman III PE, Lobanenkov VV (2001) Functional phosphorylation sites in the
C-terminal region of the multivalent multifunctional transcriptional factor CTCF. Mol Cell Biol 21: 2221-2234

Klenova E, Morse H, Ohlsson R, Lobanenkov V (2002) The novel BORIS + CTCF gene family is uniquely involved in the epigenetics of normal biology and cancer. Semin Cancer Biol 12: 399

Kollias J, Murphy CA, Elston CW, Ellis IO, Robertson JF, Blamey RW (1999) The prognosis of small primary breast cancers. Eur J Cancer 35: 908-912

Kononen J, Bubendorf L, Kallioniemi A, Barlund M, Schraml P, Leighton S, Torhorst J, Mihatsch MJ, Sauter G, Kallioniemi OP (1998) Tissue microarrays for high-throughput molecular profiling of tumor specimens. Nat Med 4: 844-847

Madjd Z, Pinder SE, Paish C, Ellis IO, Carmichael J, Durrant LG (2003) Loss of CD59 expression in breast tumours correlates with poor survival. J Pathol 200: 633-639

McCarty Jr KS, Miller LS, Cox EB, Konrath J, McCarty Sr KS (1985) Estrogen receptor analyses. Correlation of biochemical and immunohistochemical methods using monoclonal antireceptor antibodies. Arch Pathol Lab Med 109: 716-721

Ohlsson R, Renkawitz R, Lobanenkov V (2001) CTCF is a uniquely versatile transcription regulator linked to epigenetics and disease. Trends Genet 17: $520-527$

Qi CF, Martensson A, Mattioli M, Dalla-Favera R, Lobanenkov VV, Morse III HC (2003) CTCF functions as a critical regulator of cell-cycle arrest and death after ligation of the B cell receptor on immature B cells. Proc Natl Acad Sci USA 100: 633-638

Rasko JE, Klenova EM, Leon J, Filippova GN, Loukinov DI, Vatolin S, Robinson AF, Hu YJ, Ulmer J, Ward MD, Pugacheva EM, Neiman PE, Morse HC, Collins III SJ, Lobanenkov VV (2001) Cell growth inhibition by the multifunctional multivalent zinc-finger factor CTCF. Cancer Res 61: $6002-6007$

Skirnisdottir S, Eiriksdottir G, Baldursson T, Barkardottir RB, Egilsson V, Ingvarrson S (1995) High frequency of allelic imbalance at chromosome region 16q22-23 in human breast cancer: correlation with high PgR and low S phase. Int J Cancer 64: 112-116

Takai D, Gonzales FA, Tsai YC, Thayer MJ, Jones PA (2001) Large scale mapping of methylcytosines in CTCF-binding sites in the human H19 promoter and aberrant hypomethylation in human bladder cancer. Hum Mol Genet 10: 2619-2626

Ulaner GA, Vu TH, Li T, Hu JF, Yao XM, Yang Y, Gorlick R, Meyers P, Healey J, Ladanyi M, Hoffman AR (2003) Loss of imprinting of IGF2 and $\mathrm{H} 19$ in osteosarcoma is accompanied by reciprocal methylation changes of a CTCF-binding site. Hum Mol Genet 12: 535-549

Vostrov AA, Quitschke WW (1997) The zinc finger protein CTCF binds to the APBbeta domain of the amyloid beta-protein precursor promoter. Evidence for a role in transcriptional activation. J Biol Chem 272: $33353-33359$

Yeh A, Wei M, Golub SB, Yamashiro DJ, Murty VV, Tycko B (2002) Chromosome arm $16 \mathrm{q}$ in Wilms tumors: unbalanced chromosomal translocations, loss of heterozygosity, and assessment of the CTCF gene. Genes Chromosomes Cancer 35: $156-163$

Zhang R, Burke LJ, Rasko JE, Lobanenkov V, Renkawitz R (2004) Dynamic association of the mammalian insulator protein CTCF with centrosomes and the midbody. Exp Cell Res 294: 86-93 